Article

\title{
Do Coarser Gap Mosaics in Conifer Plantations Induce More Seed Dispersal by Birds? Temporal Changes during 12 Years after Gap Creation
}

\author{
Tsubasa Takano ${ }^{1}$, Yohsuke Kominami ${ }^{2}$ and Hiromi Mizunaga ${ }^{3, *}$ \\ 1 Department of Agriculture, Graduate School of Integrated Science and Technology, Shizuoka University, \\ 836 Ohya, Suruga-ku, Shizuoka 422-8529, Japan; tiara.moon.remineko5050@gmail.com \\ 2 College of Education, Shizuoka University, 836 Ohya, Suruga-ku, Shizuoka 422-8529, Japan; \\ kominami.yosuke@shizuoka.ac.jp \\ 3 College of Agriculture, Shizuoka University, 836 Ohya, Suruga-ku, Shizuoka 422-8529, Japan \\ * Correspondence: mizunaga.hiromi@shizuoka.ac.jp; Tel.: +81-54-238-4841
}

Received: 29 August 2019; Accepted: 16 October 2019; Published: 18 October 2019

\begin{abstract}
The creation of canopy gaps is thought to be an efficient silvicultural operation to diversify species composition of monoculture conifer plantations; however, the shortage of regeneration materials in overclosed plantations is one of the concerns related to this operation. Seed dispersal by frugivorous birds may play an important role in inducing the spread of native broad-leaved trees in canopy gaps in plantations in the warm temperate zone of central Japan because bird-dispersed woody species are abundant in this area. We monitored the dynamics of the abundance and species composition of bird-dispersed seeds over 12 years after gap creation in the canopy of a Japanese cypress (Chamaecyparis obtusa (Siebold et Zucc.) Endl.) plantation. We also studied the effects of gap-mosaic patterns (from many small gaps to fewer large gaps) on dispersal. We used a hierarchical Bayesian zero-inflated Poisson model to analyze the factors affecting seed dispersal by frugivorous birds. Seed dispersal by birds increased with gap age except for just after gap creation. Dispersal in coarser gap mosaics was more abundant than that in finer gap mosaics. The species diversity of dispersed seeds in each seed trap ( $\alpha$-diversity) and plot ( $\gamma$-diversity) showed similar trends in terms of temporal changes and differences between plots related to seed dispersal abundance; $\beta$-diversity did not. These trends might have been caused by shrub-vegetation development after gap creation. The effects of shrub vegetation were classified into the attraction by fruits borne within the vegetation, as well as other effects related to vegetation, such as functions of perch availability and insect presence as a food source. The presence of bird-dispersed seeds was strongly promoted by vegetation in all seasons, but only marginally by the presence of fruit-bearing vegetation. However, fruits attracted seed dispersal by frugivorous birds in the winter season. Our results suggest that both vegetation development and fruiting are important for promoting seed dispersal by frugivorous birds, and those effects are different in different seasons according to vegetation conditions and shifting food resources.
\end{abstract}

Keywords: seed dispersal; bird-dispersed seed; conifer plantation; gap mosaic; temporal change

\section{Introduction}

Forested areas in Japan account for two-thirds of the land area. In the 1950s, more than $40 \%$ of this area was replaced by monoculture plantations of conifers such as Japanese cedar (Cryptomeria japonica (L.f.) D.Don) and Japanese cypress (Chamaecyparis obtusa (Siebold et Zucc.) Endl.). Overclosed monoculture plantations, which are characterized by high density and a closed canopy, appeared in mountainous areas from the 1990s onwards as a result of stakeholders in the area losing the motivation to continue forest management. These trends have led to the degradation 
of ecological function and a decline in biodiversity [1]. Therefore, restoring these plantations by diversifying stand structure and species has been attempted in order to improve forest-ecosystem services $[2,3]$. The creation of canopy gaps to drive the regeneration of native trees is thought to be an efficient silvicultural operation for creating complex mixed forests [4-6]. Canopy gaps create a heterogeneous microclimate, and the arrangement of canopy gaps or the coarseness of the gap mosaic (from many small gaps to fewer large gaps) is closely related to the abundance of safe sites for native-tree growth $[7,8]$.

However, regenerating materials, such as advanced tree regeneration and buried seeds, are generally poor in overclosed monoculture plantations, and the poverty of the regeneration is a serious hindrance to their conversion to a mixed forest via canopy-gap creation $[9,10]$. Seed dispersal from natural forests is expected to increase the regeneration materials in plantations being rehabilitated, compensating for the poor seed bank and number of seedlings. More than $77 \%$ of tree species in laurel forests-natural forests in warm temperate zones-are bird-dispersed woody species, with wind-dispersed species only constituting 4\% [11]. The spatial-distribution pattern of seeds dispersed by birds is more heterogeneous than that of wind-dispersed seeds [12-14], and the unstable dispersal of bird-dispersed woody species might be a disadvantage in promoting the regeneration of plantations. However, the possibility of long-distance dispersal is higher in bird-dispersed woody species than in wind-dispersed species, and this feature may act as an advantage for diverse species composition in plantations distant from seed sources.

In general, dispersal of seeds by birds is well known to decrease with increasing distance from the seed source, such as natural forests [5,15-17]. It is also known that fruiting plants attract birds and promote seed dispersal by frugivorous birds $[12,16,18]$. Seed dispersal into openings such as canopy gaps, pastures, and grasslands are generally less frequent than those into forested areas $[12,15,17,19,20]$. However, if remnant trees or fruiting trees are present acting as bird perching structures or food sources, seed dispersal by birds is promoted under those trees [18,20-24]. Furthermore, in tropical pastures, bird visits and dispersals are greater in high-plant-cover patches than in lower-plant-cover patches because of the rich food resources and low predation risk [25-29]. Reid et al. (2015) found that the number of bird-dispersed seeds and species increased with vegetation development (with the passing of the years) in restoration areas [30]. Yamagawa et al. (2013) also found slightly increased dispersal into openings during the six years after clear-cutting in Japan [17]. However, most studies on seed dispersal only cover a few years, with the exception of the aforementioned Yamagawa et al. (2013) and Reid et al. (2015).

Gap arrangement in monoculture plantations is an essential aspect of the microclimate, which affects seedling development and is also assumed to affect seed dispersal. Larger gaps or wide openings might increase the risk of being preyed upon, and long distances from the boundary would hinder seed dispersal. In contrast, vigorous vegetation growth in larger gaps may attract birds by providing fruit and/or hiding places. Questions thus arise about whether fewer larger gaps or many small gaps work best to promote seed dispersal. There have been no investigations into these aspects, over either a short or long period of time.

Herein, we present a seed-dispersal study conducted over 12 years in different canopy-gap mosaics in a Japanese cypress (Chamaecyparis obtusa) plantation. We compared bird-dispersed seed abundance and species compositions relative to two main impacts: years since gap establishment and type of gap mosaic. The objectives of this study were to clarify the following questions: (1) Does bird-dispersed seed abundance increase with time after gap creation in a plantation? (2) Do finer gap mosaics or coarser gap mosaics induce more bird-dispersed seeds? (3) How do gap age and gap mosaic change the composition of bird-dispersed woody species? (4) What are the factors affecting seed dispersal by frugivorous birds in different gap-mosaic arrangements? 


\section{Materials and Methods}

\subsection{Study Site}

The study site was a 65-year-old Japanese cypress (Chamaecyparis obtusa) plantation (3 ha) in the Tenryu Forest of Shizuoka University, Hamamatsu city, central Japan (34⒌02' N, $137^{\circ} 44.67^{\prime} \mathrm{E}, 440 \mathrm{~m}$ above sea level). The plantation is located on a north-to-east steep slope of $25^{\circ}-40^{\circ}$, and soil type is classified as yellowish-brown forest soil [31]. The study site is in a warm temperate zone, and mean annual precipitation and temperature during the period of 2006 to 2009 were $2241 \mathrm{~mm}$ and $13.4{ }^{\circ} \mathrm{C}$, respectively [31]. Although Japanese cypress dominated the stand, Japanese cedar (Cryptomeria japonica) and Japanese red pine (Pinus densiflora Siebold et Zucc.) were also present. There were no bird-dispersed trees in the overstory. Stem density, mean diameter at breast height (DBH), and mean height of the plantation were $1068 \mathrm{ha}^{-1}, 24.8 \mathrm{~cm}$, and $18.1 \mathrm{~m}$, respectively. The plantation neighbored secondary evergreen broad-leaved forests that could act as seed sources for the seed dispersal of native trees, and were dominated by Fagaceae and Lauraceae species, as shown in Figure 1a.

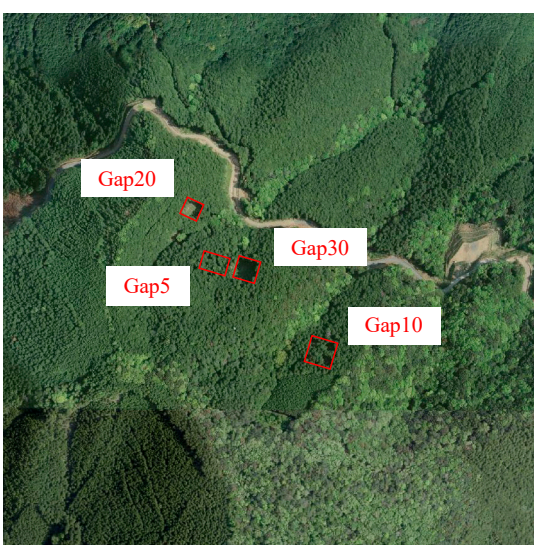

(a)

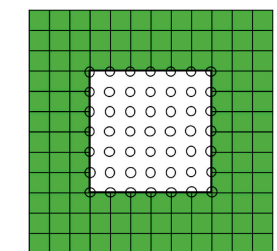

$30 \mathrm{~m} \times 30 \mathrm{~m}$

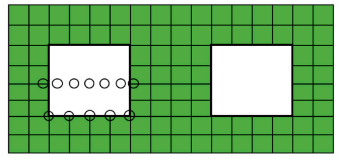

$20 \mathrm{~m} \times 20 \mathrm{~m}$

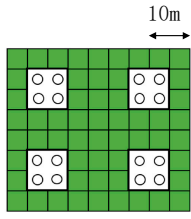

$10 \mathrm{~m} \times 10 \mathrm{~m}$

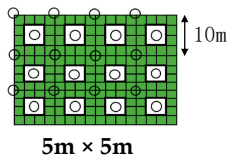

(b)

Figure 1. (a) Aerial photography of study site; red squares denote gap-mosaic experiment plots. Cypress plantation is adjacent to an evergreen broad-leaved forest, shown in lower right. (b) Four types of gap arrangements: green and white, plantation areas and canopy gaps, respectively; open circles, seed traps.

\subsection{Gap-Mosaic Design}

We established 4 plots with different aggregations of gap mosaics from the finest gap mosaic $\left(25 \mathrm{~m}^{2}\right.$ in area and 100 gaps ha $\left.^{-1}\right)$ to the coarsest $\left(900 \mathrm{~m}^{2}\right.$ and 2.78 gaps ha $\left.^{-1}\right)$ in the winters of 2006 and 2007 (Table 1, Figure 1b). The small compartment size and complex topography did not allow us to establish more than 4 plots with different gap mosaics, and there were no replications for each gap-mosaic arrangement. We cleared the vegetation by cutting shrubs or saplings in plots prior to the gap-creation process. Detailed information is available in Table S1.

Table 1. Description of gap-mosaic arrangements in the Japanese cypress plantation and number of seed traps.

\begin{tabular}{|c|c|c|c|c|c|c|c|c|c|c|c|}
\hline \multirow{2}{*}{ Plot } & \multirow{2}{*}{$\begin{array}{l}\text { Gap Size } \\
\text { (m) }\end{array}$} & \multirow{2}{*}{$\begin{array}{l}\text { Plot Area } \\
\qquad\left(\mathrm{m}^{2}\right)\end{array}$} & \multirow{2}{*}{$\begin{array}{c}\text { Year of Gap } \\
\text { Establishment }\end{array}$} & \multirow{2}{*}{$\begin{array}{c}\text { Slope } \\
\text { Direction }\end{array}$} & \multirow{2}{*}{$\begin{array}{c}\text { Gap } \\
\text { Number }\end{array}$} & \multicolumn{6}{|c|}{ Seed-Trap Number } \\
\hline & & & & & & 2006 & 2007 & 2008 & 2009 & 2014 & 2018 \\
\hline Gap5 & $5 \times 5$ & 1200 & 2006 & NW & 12 & 24 & 24 & 24 & 24 & 24 & 24 \\
\hline Gap10 & $10 \times 10$ & 1800 & 2007 & NW & 4 & - & 12 & 12 & 12 & 10 & 16 \\
\hline Gap20 & $20 \times 20$ & 3200 & 2007 & $\mathrm{E}$ & 2 & - & 12 & 12 & 12 & 12 & 12 \\
\hline Gap30 & $30 \times 30$ & 3600 & 2006 & NW & 1 & 49 & 49 & 49 & 49 & 49 & 49 \\
\hline
\end{tabular}




\subsection{Seed Rain into Gaps}

We installed seed traps (area $=0.23 \mathrm{~m}^{2}$ ) in each plot after the gaps were established, and all seeds in the traps were collected in monthly intervals during the years of 2006, 2007, 2008, 2009, 2014, and 2018 (Table 1). After collection, we sorted the seeds, identified the species, and counted each species. We excluded immature seeds and insect-damaged seeds as determined by visual observation. Seeds of bird-dispersed woody species without fruit were classified as bird-dispersed seeds, while seeds with fruit were classified as gravity-fallen seeds, dispersed directly from the mother tree to the seed trap. We excluded the seeds of Cryptomeria japonica and Chamaecyparis obtusa from data analysis as they are planted trees. Although the number and location of the seed traps differed slightly in each year of the study (Table 1), we assumed that the difference had no significant effect on the trend of temporal changes in seed rain.

\subsection{Factors Related to Seed Dispersal at 12 Years after Gap Creation}

We conducted research of the vegetation conditions around each seed trap in October 2018 to clarify the effects on seed dispersal by birds. We recorded the species, $\mathrm{DBH}$, tree height, and stem number of trees and shrubs $>1.3 \mathrm{~m}$ in height above the ground in quadrates $(2 \times 2 \mathrm{~m})$ located nearer than $5 \mathrm{~m}$ from the seed traps. We also recorded whether fruits of bird-dispersed plant species were borne or not (as a binary variable) inside an area $3 \mathrm{~m}$ from each seed trap at 1-month intervals from August to December 2018. The total basal area per area of trees and shrubs except for planted trees near each seed trap was used as a "vegetation index", and whether fruit was borne or not near each seed trap was used as a "fruiting index" for statistical analysis.

\subsection{Data Analysis}

\subsubsection{Seed Dispersal by Frugivorous Birds}

We evaluated seed dispersal by birds using 3 indices: number of dispersed seeds, estimated number of dispersed fruits, and proportion of seed traps with dispersed seeds. Seed count is a basic and simple dispersal index but may be biased toward species that have many small seeds in a fruit. Fruit count was calculated by dividing the seed count by the number of seeds contained in a fruit of each species according to descriptions in the literature [32,33], enabling us to prevent species bias. In the case of unidentified species, including Callicarpa and Rubus, we used C. japonica because the fruit form of Callicarpa is not so different between species, and R. crataegifolius because there were many R. crataegifolius in the study site. The third index, the proportion of dispersed traps, was calculated from Equation (1):

$$
P=\Sigma M t / N \cdot T \times 100
$$

where $M t, N$, and $T$ are the number of seed traps that had a dispersed seed during the observation period, the total number of seed traps, and the sampling repeats per year, respectively.

\subsubsection{Effect of Gap Mosaic and Age}

We analyzed the effect of the gap-mosaic pattern and gap age (time passed after gap creation) on dispersed seed intensities using the generalized linear model (GLM) and Tukey's honestly significant difference (HSD) test between plots and observation years, respectively. We used Poisson families for seed counts and fruit counts, and binomial linking with "logit" for the proportion of dispersed seed traps.

\subsubsection{Ordination of Species Composition and Calculation of Species Diversity}

We classified dispersed species via 3 ecological aspects according to descriptions in the literature: First, dispersal types (frugivore bird dispersal, wind dispersal, and others, e.g., gravity, caching); 
second, growth forms (tree, shrub, vine); and third, successional stages (forest, secondary forest, and pioneer) $[34,35]$.

We compared the species diversity of bird-dispersed woody species between plots and observation years. We calculated $\alpha-, \beta-$, and $\gamma$-diversity on the basis of the number of dispersed fruits in each seed trap using Equations (2)-(4) [36]:

$$
\begin{gathered}
D \alpha=\exp (-\Sigma(\Sigma p i \times \log (p i)) / N) \\
D \beta=D \gamma / D \alpha \\
D \gamma=\exp \left(-\Sigma\left(\sum p i j / N\right) \times \log \left(\sum p i j / N\right)\right)
\end{gathered}
$$

where $D \alpha, D \beta$, and $D \gamma$ are $\alpha-, \beta$-, and $\gamma$-diversity, respectively; and $N$ and pij are the number of seed traps and proportion of species $i$ 's fruits in trap $j$, respectively.

We visualized the species composition of bird-dispersed seeds using nonmetric multidimensional scaling (nMDS) in each seed trap and each measuring year, using Jaccard distance matrices for dissimilarity.

\subsubsection{Bayesian Model for Factors Determining Dispersal Frequency}

We used a hierarchical Bayesian zero-inflated Poisson model to analyze factors affecting seed dispersal by birds. The effects of the vegetation index and fruiting index around the seed traps on fruit counts in each seed trap in each month were evaluated during the term from August to December 2018. As the fruiting index may have been related to the vegetation index, we incorporated this relation into the model to prevent confounding (Table 2). Zero-inflated Poisson (ZIP) is a function of zero-inflated Poisson distribution consisting of a binomial distribution with proportion $q$ and Poisson distribution with mean lambda.

\begin{tabular}{|c|c|c|}
\hline Type & Variables & Description \\
\hline Data & $\begin{array}{c}S \\
V g \\
F t \\
M\end{array}$ & $\begin{array}{l}\text { Fruit counts } \\
\text { Vegetation index } \\
\text { Fruiting index } \\
\text { Month }\end{array}$ \\
\hline Parameters & $\begin{array}{c}a(M) \\
b(M, F t) \\
c(M) \\
d(M, F t) \\
p f(M) \\
\text { pic }(M) \\
\text { a_base-pic_base } \\
\text { std_a-std_pic }\end{array}$ & $\begin{array}{l}\text { Effect of vegetation on dispersal presence } \\
\text { Effect of fruiting on dispersal presence } \\
\text { Effect of vegetation on fruit counts } \\
\text { Effect of fruiting on fruit counts } \\
\text { Effect of vegetation on fruiting } \\
\text { Intercept on fruiting } \\
\text { Hyperparameters of parameters } a, b, c, d, p f \text {, } \\
\text { and pic for average and standard deviation }\end{array}$ \\
\hline & Models & 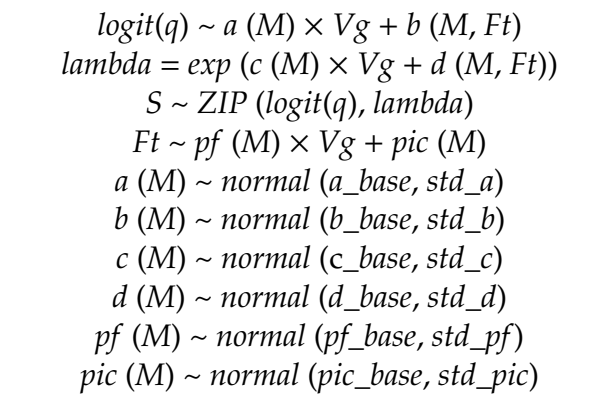 \\
\hline
\end{tabular}

Table 2. Formula of hierarchical Bayesian zero-inflated Poisson model with each variable and its description. 
We used free statistical software R (https://www.r-project.org) for all statistical analyses, and packages "multcomp" (https://cran.r-project.org/web/packages/multcomp/index.html), "vegan" (https://www.rdocumentation.org/packages/vegan/versions/2.4-2), and "rstan" (https://cran.r-project. $\mathrm{org} /$ web/packages/rstan/index.html) for multiple comparisons of the GLM, nMDS, and Markov chain Monte Carlo (MCMC) simulation for the Bayesian model.

\section{Results}

We found 6501 seeds belonging to 54 species in the experiment seed traps during the six collection years over the total twelve years. Of these, $87.6 \%$ belonged to 37 bird-dispersed woody species, and $10.8 \%$ belonged to 11 wind-dispersed species. Additionally, $86.6 \%$ belonged to 23 shrub species, and $12.6 \%$ belonged to 25 tree species (Table S2).

\subsection{Temporal Changes in Seed Rain}

Counts of wind-dispersed seeds in each seed trap increased in the first few years, but after that, the counts stagnated or decreased, and there were no clear trends of differences between plots (Figure S1a).

Counts of bird-dispersed seeds and fruits were low just after gap creation, but generally increased with time after 2009, with the exception of Gap5 and Gap30 from 2009 to 2014 (Figure 2a,b, $p<0.05$ ). When the seeds of Callicarpa were excluded, the seed and fruit counts increased after 2009 in all plots (Figure S1b, $p<0.05$ ). The proportions of traps with seeds present consistently increased with gap ages (Figure $2 c, p<0.05$ ). The number of dispersed seeds, fruits, and the proportion of seed traps with dispersed seeds in Gap20 and Gap30 (coarser gaps) were significantly higher than those in Gap5 and Gap10 in 2018 (finer gaps, Figure 2, $p<0.05$ ).

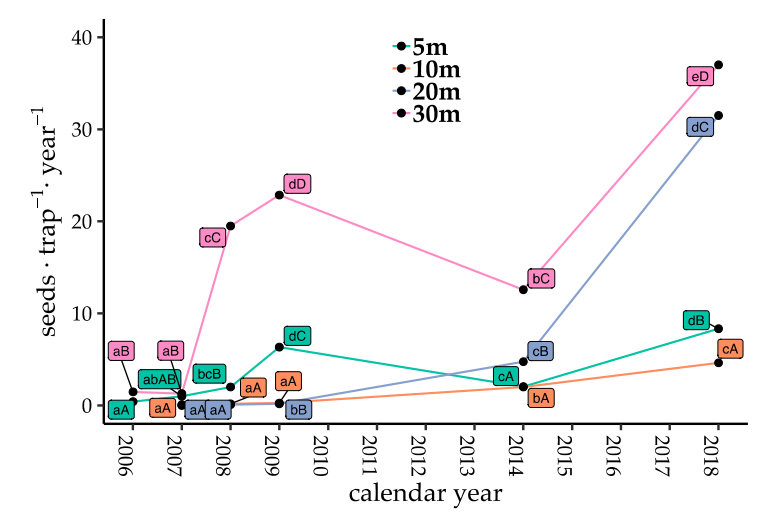

(a)

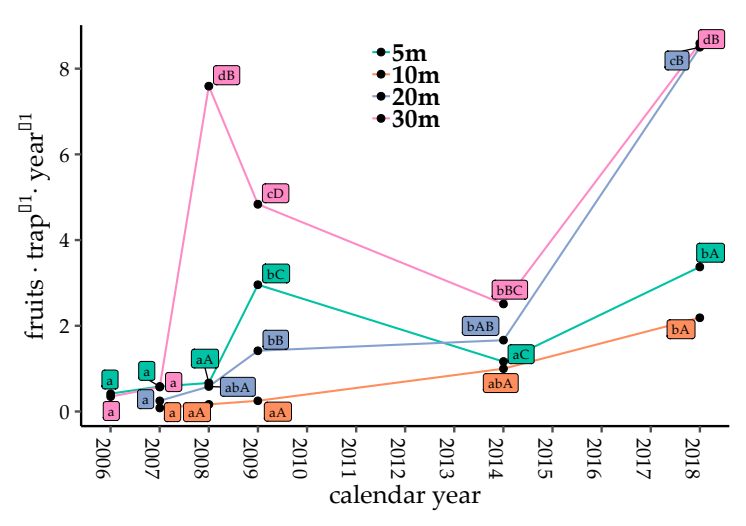

(b)

Figure 2. Cont. 


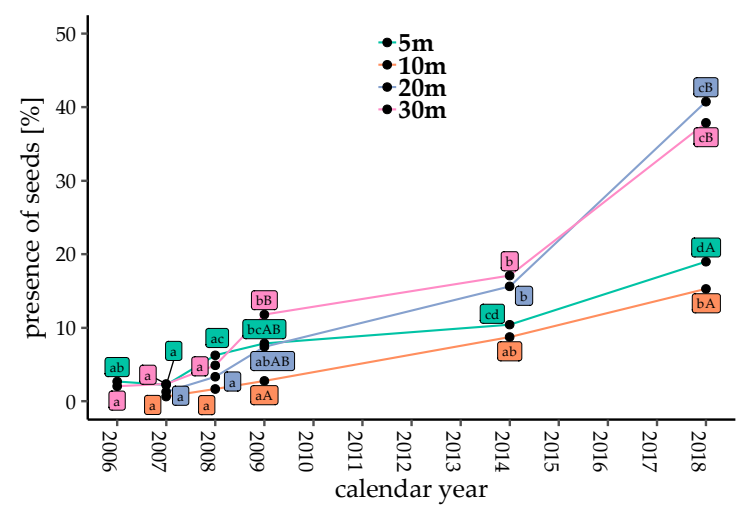

(c)

Figure 2. Temporal changes in seed dispersal of bird-dispersed woody species in each plot. (a) Number of dispersed seeds; (b) number of dispersed fruits; and (c) proportion of seed traps with dispersed seeds at each collection. Different lowercase letters denote significant differences among measuring years, and uppercase letters denote significant differences among plots from multiple comparisons (generalized linear model (GLM), $\alpha=0.05)$.

\subsection{Transitions in Dispersed-Species Composition}

The $\alpha$ - and $\gamma$-diversities of dispersed species in each seed trap increased according to gap age and were especially high in 2018 (Figure 3a,c), while $\beta$-diversity increased in the years just after gap creation, but became stable after 2009 (Figure 3b). $\alpha$ - and $\gamma$-diversity were higher in coarser gap mosaics (Gap20 and Gap30) than in finer gap mosaics (Gap5 and Gap10; Figure 3a,c). On the contrary, regarding $\beta$-diversity, there were only small differences between plots in 2018 (Figure 3b).

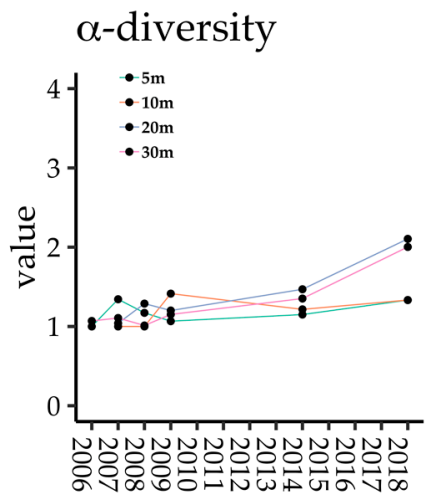

(a)

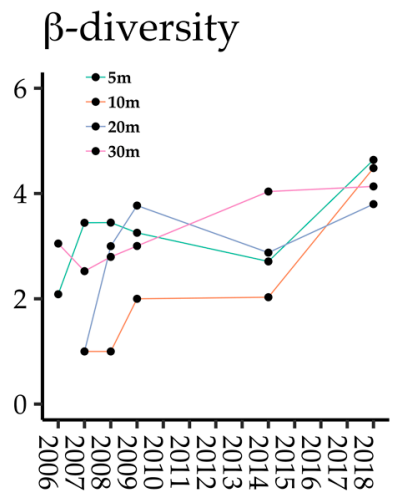

(b)

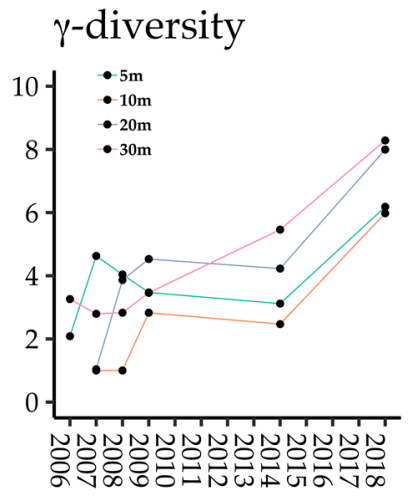

(c)

Figure 3. Temporal changes in (a) $\alpha_{--},(\mathbf{b}) \beta-$, and (c) $\gamma$-diversities in each plot.

Species compositions differed more between gap ages than plots (Figure 4). They showed a concentrative distribution in the first few years, but wide-range distribution in 2014 and 2018 (Figure 4a). While species compositions were different among gap ages, there were no consistent trends in axes or between the species groups (Figure S2). 


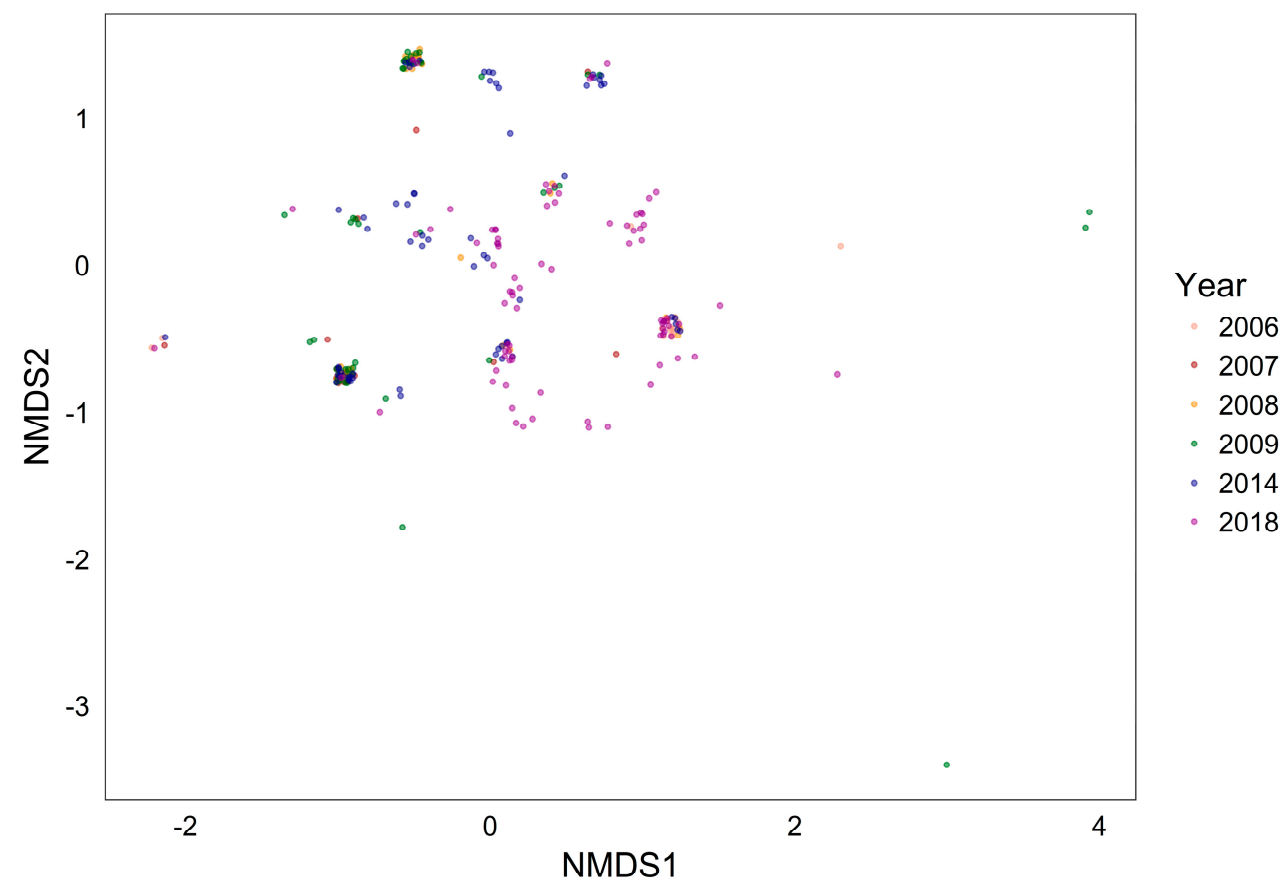

(a)

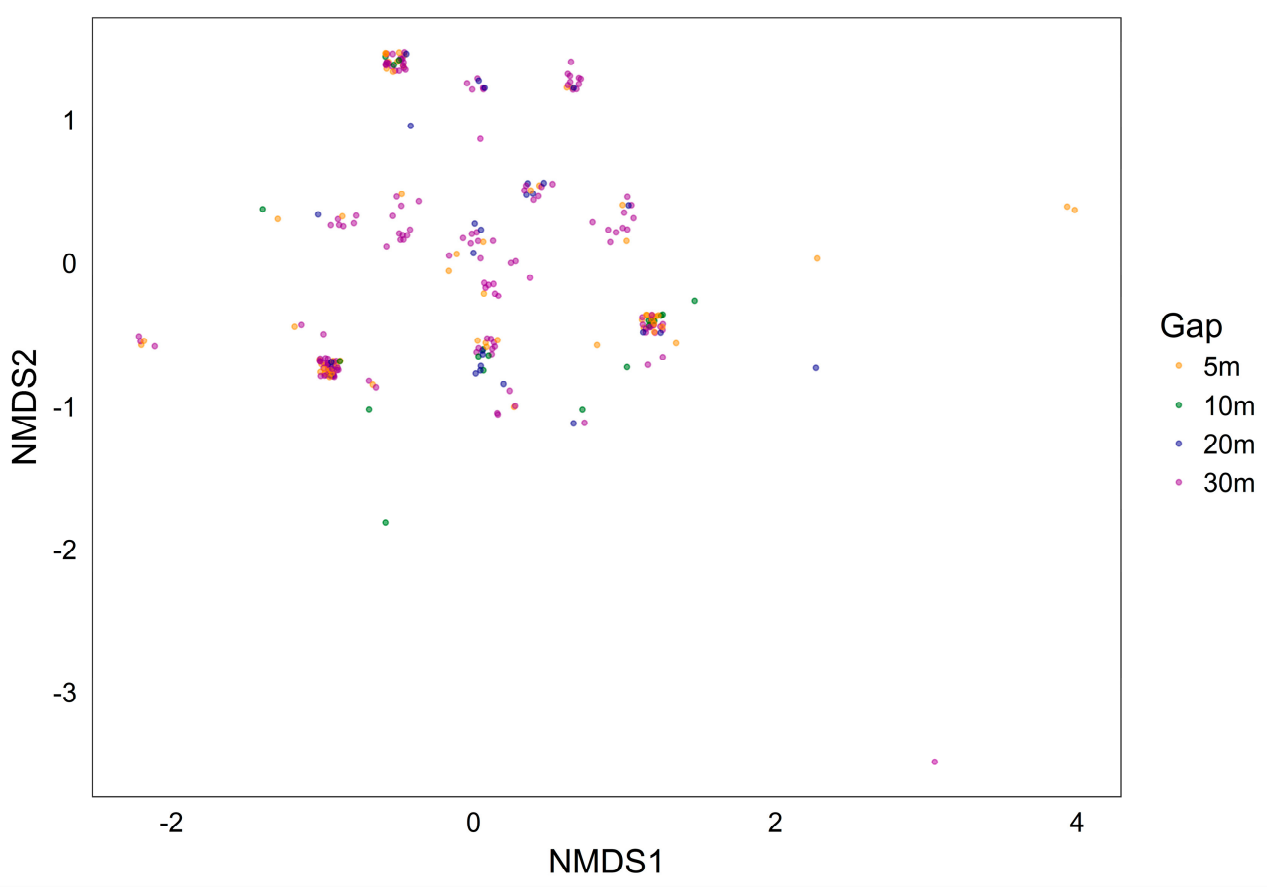

(b)

Figure 4. First two axes of two-dimensional nonmetric multidimensional scaling (nMDS) fit based on Jaccard distances $(k=2$, stress $=0.093)$. Each point denotes a seed trap. (a) Different colors denote each measuring year; (b) different colors denote each gap mosaic. We excluded species with an extremely low frequency (less than four fruits) from analysis, and used the "jitter" function to display overlapping coordinates. 


\subsection{Factors for Seed Dispersal by Frugivorous Birds}

The vegetation index contributed to the occurrence of seed dispersal in all seasons, and the fruiting index contributed to the occurrence of seed dispersal in August (Figure 5a,b). Vegetation had a positive effect on fruit counts in September, October, and November, but had a negative effect in December (Figure 5c). Fruiting had a positive effect on fruit counts in November and December (Figure 5d).

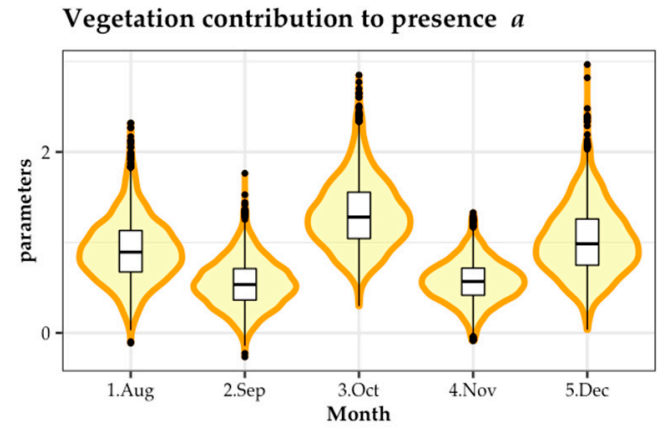

(a)

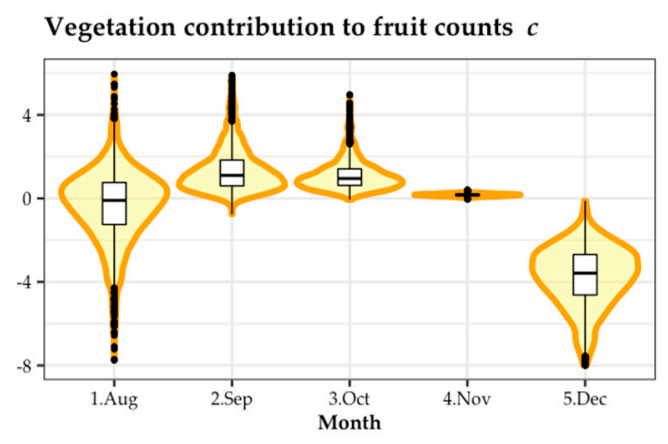

(c)

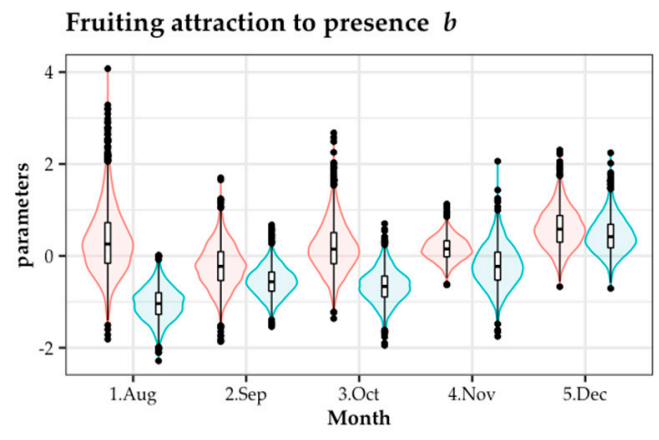

(b)

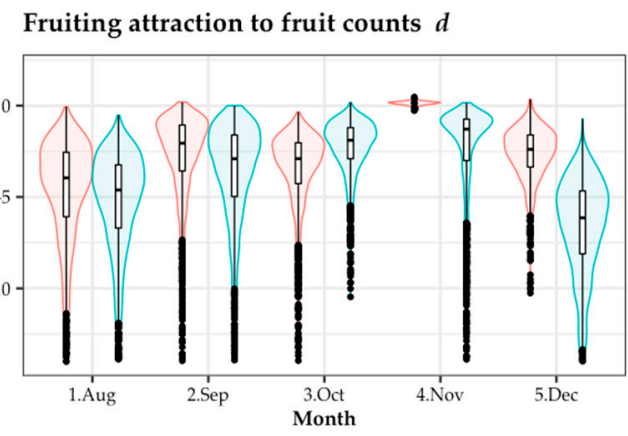

(d)

Figure 5. Bayesian analysis of the number of dispersed fruits in each seed trap from August to December of 2018. (a) Vegetation contribution to seed presence; (b) fruiting attraction to seed presence; (c) vegetation contribution to fruit counts; and (d) fruiting attraction to fruit counts. Red and blue in (c,d) denote parameters of fruit existence and fruit absence, respectively.

\section{Discussion}

\subsection{Does Bird-Dispersed Seed Abundance Increase with Time after Gap Creation in a Plantation?}

Previous studies have shown that the abundance of bird-dispersed seeds increases with the passing years [17], and the abundance of dispersed seeds remarkably increases during the first 10 years [30]. These results are thought to be the consequence of vegetation development. Our results also showed that, while wind-dispersed seed abundance did not increase with the passing years, bird-dispersed seed and fruit abundance was low just after gap creation, but generally increased from the third year after gap creation onwards. The number of dispersed seed traps consistently increased with gap age and was especially significant from eight to twelve years after gap creation. Birds generally avoid open sites because of the lack of food resources or perching structures, and the risks of being preyed upon $[12,15,17,19,20,37]$. Thus, food resources and perching structures supplied by vegetation promote bird visits and dispersal [18,20-24]. We expect that vegetation development with the passing years enriched those attracting factors and promoted seed dispersal.

The decrease in the number of dispersed seeds and fruits in Gap30 from 2009 to 2014 can probably be attributed to the seed dispersal of Callicarpa, which is one of the dominant dispersed species, it being 
intensively dispersed in 2008 and 2009 (Figure S1b). The greater dispersal of Callicarpa could be due to fruiting variance of Callicarpa over the years or other uncertain factors.

The dynamics of seed dispersal, as presented above, would suggest that, if we expect to use seed dispersal by birds as a means of inducing the spread of native tree species, we need to evaluate it over a large time scale.

\subsection{Do Finer or Coarser Gap Mosaics Induce More Bird-Dispersed Seeds?}

While there have been many studies on seed dispersal into open sites, there have been no studies comparing different gap-mosaic arrangements. Our gap-mosaic arrangements (from many small gaps to fewer large gaps) displayed a trade-off, leading to vigorous vegetation development in the coarser gaps, and lower risks of being preyed upon in the finer gaps. Seed dispersal by birds was greater in coarser gaps (larger gaps) than in finer gaps (smaller gaps) from the four plots along the gradient of gap-mosaic coarseness. This result may show the importance of shrub vegetation for inducing seed dispersal by birds, although the sample size of gap-mosaic arrangement was small. It is well known that the structural complexities of vegetation influence the bird community in Japan, and the richness of understory vegetation is important for birds that mainly depend on shrubs [38,39]. Gap5, which had low seed dispersal by birds, was almost completely closed by tall canopy trees and might have had low risk of predation. The food resources and perching function of shrub vegetation have been suggested to be larger than those of planted conifer trees, and the effect of shrub vegetation might become significant according to shrub development. The attraction for birds was known to be different between successional stages, and between shrubs and trees. Pioneer species were often composed of bird-dispersed woody species in conifer plantations [37]. In addition, fruit of shrub species might be more attractive than tree species due to their color and small size [40]. Therefore, the plants that developed in the gaps, which were mostly made up of pioneer or shrub species, may have had advantages in terms of attracting birds.

Since the effect of gap-mosaic arrangement on the development process of vegetation differed for each stand, the degree of the positive effect of gap size on seed dispersal by birds was expected to be variable among stands. There is the possibility of a negative gap-size effect caused by the distance from the gap edge depending on the stand situation, although we did not detect this. Because the relationship between gap-mosaic arrangement and seed rain of bird-dispersed seeds is expected to be variable for the above reasons, our results should be examined by using many samples with various conditions. Although our results provide limited information on the relationship due to the small sample size, our findings regarding the positive contribution of developed shrub vegetation after gap creation in terms of seed dispersal by birds provides valuable information when considering the mechanisms involved in gap-mosaic arrangement and seed dispersal.

\subsection{How do Gap Age and Gap-Mosaic Arrangement Change Composition of Bird-Dispersed Woody Species?}

Yamagawa et al. (2013) found that the number of bird-dispersed woody species increased with the passing years. Our study agreed with this report, showing that dispersed-species diversity in each seed trap ( $\alpha$-diversity) and plot ( $\gamma$-diversity) increased with gap age, and was greater in coarser gaps than in finer gaps. These trends in gap-mosaic arrangement, if we regard gaps as islands, could be explained by using the widely applied theory of island biogeography, in which large islands contain more abundant species than small islands [41]. As the increment pattern and difference between plots of $\alpha$-diversity were similar to the increase in the proportion of dispersed traps (Figure 2c), vegetation development might also have a function in enhancing species richness. However, diversity between seed traps ( $\beta$-diversity) was invariant and similar to that in other plots. The difference in species composition among traps did not significantly increase or differ between plots. These results related to $\beta$-diversity might be because of "nestedness" among seed traps by dominant dispersed species [42], because seed rain of bird-dispersed seeds consisted of a large number of seeds from a few species and a small number of seeds from a greater number of species. An unclear difference in spatial heterogeneity within the 
plots was also found and is shown in Figure 4: the difference in species composition between plots was smaller than that between measuring years. The concentrated trend in the species composition of traps in the first few years (Figure 4), and the small $\beta$-diversity in 2006 and 2007 show that species compositions were quite similar between traps in the early stages of vegetation development after gap creation. The clear difference in dispersed species compositions between years was possibly caused by fruiting variation across the years, such as "mast seeding" in each species.

\subsection{Effect of Natural Forests}

Although we have not conducted analysis regarding seed sources or seed-dispersal distances, it is possible to say that seeds were less dispersed into Gap10, which is adjacent to a natural forest, than into Gap20, which is farther away from the natural forest (Table S1). It is known that short distances or the existence of an abundant forest does not always promote seed dispersal by birds or the recruitment of bird-dispersed woody species $[30,43,44]$. This concept may also apply to our research, because the birds preferred rich vegetation and fruits over proximity to the seed-source forest. In this study area, there were several harvesting trails with small openings, and we could see small shrub patches there; thus, birds might disperse seeds into the gaps from those seed sources. Small bird species, which prefer understory shrubs, might contribute to the dispersal of small shrub seeds $[32,40,45]$. In contrast, the dispersal of tree species is well known to depend on widely moving bird species with large body sizes, such as Hypsypetes amaurotis, which disperse seeds at least $300 \mathrm{~m}$ away $[46,47]$. The unclear dependence on distance from the natural forest in this area can possibly be explained by the relationship between small birds and shrub species, which were abundant in the dispersed seeds (Table S2).

\subsection{What Are Factors Affecting Seed Dispersal by Frugivorous Birds in Different Gap-Mosaic Arrangements?}

Fruiting in gaps has been suggested as a possible explanation for the contribution of vegetation to inducing bird-dispersed seeds $[18,21-23]$, but no previous study separated the effects of vegetation development and fruiting in a real-world situation. Our study attempted to clarify the contributions of each effect by performing analysis that took into consideration the confounding effect of vegetation development and fruiting. In addition, the number of dispersed fruits showed obvious zero-inflated Poisson distribution. Between model parameters $a$ and $b$, which represent occurrence of seed dispersal by birds $q$, there was a restricting factor for dispersal; and between $c$ and $d$, which represent accumulation of seed dispersal by birds lambda, there was the factor of repeated dispersal events during the period.

The presence of dispersal was promoted by vegetation ( $a$ in Figure 5$)$ in all months, and by fruiting $(b$ in Figure 5) in August. This indicates that poor vegetation development and poor fruiting in August could be restricting factors for seed dispersal by birds. However, the contribution of fruiting to dispersal in other seasons was small. Mallotus japonicus, a tree species that bears dry fruit, mainly fruited within gaps in August. Because there were relatively few fruits in August and M. japonicus had rich fruits in its large crown, the fruits of $M$. japonicus might be distinct within the gaps; thus, fruiting had a greater attracting effect on dispersal presence in August.

The fact that the vegetation effect ( $c$ in Figure 5 ) on dispersed fruit counts was negative in December, and the fruiting effect ( $d$ in Figure 5 ) was markedly positive in November and December may correlate with vegetation conditions or shifting food resources. In summer, plants have rich leaves, there are a lot of insects, and there is generally less fruiting; on the contrary, in winter, plants defoliate leaves, have poor insect numbers, and rich fruiting. Studies on tropical opening restoration sites found that larger patches where plant cover is high contain rich insect communities, and receive many bird visits [26-30]. Most bird species in Japan are generalists that eat fruits, seeds, and insects [48,49]. Birds eat mainly insects in summer, which is their breeding season; after that, in autumn and winter, they mainly eat fruits $[37,49]$. Therefore, it is important to consider that birds may visit gap mosaics not only for fruit but also for insects. 
Our results suggest that both vegetation development and fruiting are important for promoting seed dispersal by birds, and those effects are different in different seasons according to vegetation conditions and shifting food resources.

Our study provides information regarding seed dispersal by birds obtained from longer-term observation after mosaic treatment than other similar studies using seed traps. Long-term observations, such as long-term ecological research (LTER), have contributed to revealing the forest dynamics in the world, although most of studies have been conducted in a single site [50-54]. Their contributions were facilitated by being able to link and compare with information from other LTER sites. The response of seed dispersal by birds to the gradient of gap coarseness only provided limited information due to disadvantages such as the lack of replications; however, disadvantages are expected to have a small effect on the findings related to the contributions of shrub vegetation to seed dispersal and the increase of seed rain related to gap age. Our study should be linked to other long-term observations after gap-mosaic treatments in different sites and different forest types. We expect our study to be a pioneer for other studies regarding seed rain after gap creation in forests.

\section{Conclusions}

Seed dispersal by frugivorous birds, as measured by using seed counts, fruit counts, and the proportion of dispersed seed traps, was low in the few years after gap creation, but increased remarkably after 2009. Coarser gap mosaics promoted seed dispersal by birds, which may show the greater importance of shrub vegetation than overstory coniferous trees. Bird-dispersed woody species diversity in each seed trap ( $\alpha$-diversity) and plot ( $\gamma$-diversity) also showed similar trends. However, diversity between seed traps ( $\beta$-diversity) only increased in the first few years after gap creation, and no clear difference between plots was observed. The spatial heterogeneity of species composition did not change after 2009, although species composition changed according to the measuring year due to fruiting fluctuations. Vegetation contributed to dispersal presence in all seasons, but had a negative effect on fruit counts in December. Fruiting affected the promotion of dispersal presence in August and fruit counts in winter, when the vegetation leaves had been shed. Our study confirmed the results of previous studies, and revealed that the effect of fruit and vegetation on seed dispersal, which is well known in tropical opening sites [55-57], is applicable in canopy gaps in conifer plantations.

Supplementary Materials: The following are available online at http:/www.mdpi.com/1999-4907/10/10/918/s1, Table S1: Additional descriptions of experimental plots; Table S2: List of dispersed species and each dispersal type, growth form, species group, number of dispersed seeds, and proportion of number of seeds; Table S3: Bird-dispersed seed existence in each plot and measuring year; Table S4: GLM results as an example; Table S5: GLM results as an example; Table S6: Result of Bayesian analysis. Figure S1: Temporal changes in seed dispersal in each plot; Figure S2: First two axes of a two-dimensional nonmetric multidimensional scaling fit based on Jaccard distances.

Author Contributions: Conceptualization, H.M.; data curation, T.T.; formal analysis, T.T., Y.K. and H.M.; funding acquisition, H.M.; investigation, T.T.; methodology, T.T. and Y.K.; project administration, H.M.; software, H.M.; supervision, H.M.; writing-original draft, T.T.; writing-review and editing, Y.K. and H.M.

Acknowledgments: We would like to thank Hayahito Yazawa and Atsushi Usami for establishing the study plots, and Hiroki Yasue, Satoshi Ikeda, and Noriyuki Ikeda for carrying out the experiments. We also thank Masaaki Naramoto and the members of the Silviculture laboratory, Shizuoka University for helping with the experiments and offering advice on our study.

Conflicts of Interest: The authors declare no conflict of interest.

\section{References}

1. Seiwa, K. Steps in recovering biodiversity of conifer plantations: An effective combination of edge- and thinning effects. Jpn. J. Ecol. 2013, 63, 251-260. (In Japanese)

2. Niiyama, K.; Ogawa, M.; Kushima, H.; Takahashi, K.; Sato, T.; Sakai, T.; Tanouchi, H. Collection and Evaluation of Literatures Related to Broadleaf Tree Regeneration for Leading Artificial Coniferous Forests to Broadleaf Forests. J. Jpn. For. Soc. 2010, 92, 292-296. [CrossRef] 
3. Tanouchi, H. Target Forest Type and Standard for Broadleaf Tree Regeneration. For. Sci. 2010, 59, $22-25$. (In Japanese)

4. Ito, S.; Ishigami, S.; Mizoue, N.; Buckley, G.P. Maintaining plant species composition and diversity of understory vegetation under strip-clearcutting forestry in conifer plantations in Kyushu, southern Japan. For. Ecol. Manag. 2006, 231, 234-241. [CrossRef]

5. Utsugi, E.; Kanno, H.; Ueno, N.; Tomita, M.; Saitoh, T.; Kimura, M.; Kanou, K.; Seiwa, K. Hardwood recruitment into conifer plantations in Japan: Effects of thinning and distance from neighboring hardwood forests. For. Ecol. Manag. 2006, 237, 15-28. [CrossRef]

6. Zhu, J.J.; Yang, K.; Yan, Q.L.; Liu, Z.G.; Yu, L.Z.; Wang, H.X. Feasibility of implementing thinning in even-aged Larix olgensis plantations to develop uneven-aged larch-broadleaved mixed forests. J. For. Res. 2010, 15, 71-80. [CrossRef]

7. Mizunaga, H. Do finer gap mosaics provide a wider niche for Quercus gilva in young Japanese cedar plantations than coarser mosaics? Simulation of spatial heterogeneity of light availability and photosynthetic potential. Can. J. For. Res. 2007, 37, 1545-1553. [CrossRef]

8. Fujishima, M.; Naramoto, M.; Mizunaga, H. Simulation of strip-gap arrangement in cedar plantations to regulate the light environment and competition between dwarf bamboo and beech seedlings. Forestry 2011, 84, 505-515. [CrossRef]

9. Tanaka, H.; Tanouchi, H.; Sato, T.; Masaki, T.; Akashi, N.; Takahashi, K.; Kon, H.; Seiwa, K.; Shimada, H.; Nagaike, T.; et al. Handbook of Broadleaf Tree Regeneration 2010; Tanouchi, H., Tanaka, H., Hirata, A., Eds.; Forestry and Forest Products Research Institute: Kochi, Japan, 2010. (In Japanese)

10. Tanaka, H.; Tanouchi, H.; Mizunaga, H.; Masaki, T.; Kominami, Y.; Koyama, Y.; Nagaike, T.; Sato, A.; Yamanaka, T.; Kayama, M.; et al. Handbook of Broadleaf Tree Regeneration 2012; Tanouchi, H., Tanaka, H., Hirata, A., Eds.; Forestry and Forest Products Research Institute: Kochi, Japan, 2012. (In Japanese)

11. Masaki, T. Current and future studies on seed dispersal by vertebrates in Japan. Jpn. J. Ecol. 2009, 59, 13-24.

12. Masaki, T.; Kominami, Y.; Nakashizuka, T. Spatial and seasonal patterns of seed dissemination of Cornus controversa in a temperate forest. Ecology 1994, 75, 1903-1910. [CrossRef]

13. Nanami, S.; Kawaguchi, H.; Yamakura, T. Dioecy-induced spatial patterns of two codominant tree species, Podocarpus nagi and Neolitsea aciculata. J. Ecol. 1999, 87, 678-687. [CrossRef]

14. Clark, C.J.; Poulsen, J.R.; Bolker, B.M.; Connor, E.F.; Parker, V.T. Comparative seed shadows of bird-, monkey-, and wind-dispersed trees. Ecology 2005, 86, 2684-2694. [CrossRef]

15. Hoppes, W.G. Seedfall pattern of several species of bird-dispersed plants in an Illinois woodland. Ecology 1988, 69, 320-329. [CrossRef]

16. Kon, H.; Akashi, N.; Minamino, K.; Kuramoto, S.; Iida, S. Seed dispersal of broad leaved species in Abies sachalinensis plantations on central Hokkaido, Japan. Jpn. J. Ecol. 2013, 63, 211-218. (In Japanese)

17. Yamagawa, H.; Ito, S.; Nakao, T. Seed dispersal in clear-cut stands adjacent to lucidophyllous forest in 1 to 6 years after clear-cut. Jpn. J. Ecol. 2013, 63, 219-228. (In Japanese)

18. Hoppes, W.G. Pre-and post-foraging movements of frugivorous birds in an eastern deciduous forest woodland, USA. Oikos 1987, 49, 281-290. [CrossRef]

19. Gorchov, D.L.; Cornejo, F.; Ascorra, C.; Jaramillo, M. The role of seed dispersal in the natural regeneration of rain forest after strip-cutting in the Peruvian Amazon. Vegetatio 1993, 107, 339-349.

20. Carlo, T.A.; Morales, J.M. Generalist birds promote tropical forest regeneration and increase plant diversity via rare-biased seed dispersal. Ecology 2016, 97, 1819-1831. [CrossRef]

21. McDonnell, M.J.; Stiles, E.W. The structural complexity of old field vegetation and the recruitment of bird-dispersed plant species. Oecologia 1983, 56, 109-116. [CrossRef]

22. Guevara, S.; Purata, S.E.; Van der Maarel, E. The role of remnant forest trees in tropical secondary succession. Vegetatio 1986, 66, 77-84.

23. Herrera, J.M.; Garcia, D. The role of remnant trees in seed dispersal through the matrix: Being alone is not always so sad. Biol. Conserv. 2009, 142, 149-158. [CrossRef]

24. Pizo, M.A.; dos Santos, B.T.P. Frugivory, Post-feeding Flights of Frugivorous Birds and the Movement of Seeds in a Brazilian Fragmented Landscape. Biotropica 2011, 43, 335-342. [CrossRef]

25. Suhonen, J. Predation risk influences the use of foraging sites by tits. Ecology 1993, 74, 1197-1203. [CrossRef] 
26. Fink, R.D.; Lindell, C.A.; Morrison, E.B.; Zahawi, R.A.; Holl, K.D. Patch Size and Tree Species Influence the Number and Duration of Bird Visits in Forest Restoration Plots in Southern Costa Rica. Restor. Ecol. 2009, 17, 479-486. [CrossRef]

27. Cole, R.J.; Holl, K.D.; Zahawi, R.A. Seed rain under tree islands planted to restore degraded lands in a tropical agricultural landscape. Ecol. Appl. 2010, 20, 1255-1269. [CrossRef]

28. Morrison, E.B.; Lindell, C.A.; Holl, K.D.; Zahawi, R.A. Patch size effects on avian foraging behaviour: Implications for tropical forest restoration design. J. Appl. Ecol. 2010, 47, 130-138. [CrossRef]

29. Lindell, C.A.; Reid, J.L.; Cole, R.J. Planting Design Effects on Avian Seed Dispersers in a Tropical Forest Restoration Experiment. Restor. Ecol. 2013, 21, 515-522. [CrossRef]

30. Reid, J.L.; Holl, K.D.; Zahawi, R.A. Seed dispersal limitations shift over time in tropical forest restoration. Ecol. Appl. 2015, 25, 1072-1082. [CrossRef]

31. Forest Ecosystem Section, Center for Education and Research in Field Sciences, Faculty of Agriculture, Shizuoka University. Available online: http://fc-forecol.agr.shizuoka.ac.jp/wordpress/ (accessed on 13 August 2019).

32. Kominami, Y.; Sato, T.; Takeshita, K.; Manabe, T.; Endo, A.; Noma, N. Classification of bird-dispersed plants by fruiting phenology, fruit size, and growth form in a primary lucidophyllous forest: An analysis, with implications for the conservation of fruit-bird interactions. Ornithol. Sci. 2003, 2, 3-23. [CrossRef]

33. Nakayama, S.; Inokuchi, M.; Minamitani, T. Seeds of Wild Plants in Japan; Tohoku University Press: Sendai, Japan, 2000. (In Japanese)

34. Kitagawa, M.; Miyawaki, A.; Okuda, S.; Mochizuki, R. Handbook of Japanese Vegetation; Shibundo: Tokyo, Japan, 1978. (In Japanese)

35. Satake, Y.; Hara, H.; Watari, S.; Tominari, T. Wild Flowers of Japan; Heibonsha: Tokyo, Japan, 1989. (In Japanese)

36. Magurran, A.E. Biological Diversity; Oxford University Press: Oxford, UK, 2011.

37. Sato, S.; Sakai, A. Contribution of seed dispersal by birds on vegetation recoverty after clear-cutting of a coniferous plantation. Appl. For. Sci. 2003, 12, 23-28.

38. Ichinose, T.; Katoh, K. A Relationship between Bird Communities and Vegetation Structure on Isolated Woodlots in Wintering Season in Tokorozawa City, Saitama Pref. J. Jpn. Inst. Landsc. Archit. 1995, 59, 73-76. [CrossRef]

39. Toyoshima, Y.; Yamaura, Y.; Yabuhara, Y.; Nakamura, F. A preliminary study on the effects of line and selective thinning on bird communities in Hokkaido, northern Japan. J. For. Res. 2013, 24, 553-559. [CrossRef]

40. Nakanishi, H. Fruit color and fruit size of bird-disseminated plants in Japan. Vegetatio 1996, 123, $207-218$. [CrossRef]

41. MacArthur, R.H.; Wilson, E.O. An equilibrium theory of insular zoogeography. Evolution 1963, 17, $373-387$. [CrossRef]

42. Baselga, A.; Orme, C.D.L. betapart: An R package for the study of beta diversity. Methods Ecol. Evol. 2012, 3, 808-812. [CrossRef]

43. Hirata, R.; Hata, K.; Sone, K. Seed Dispersal by Frugivorous Birds in a Coniferous Plantation. J. Jpn. For. Soc. 2006, 88, 515-524. [CrossRef]

44. Gonzales, R.S.; Nakashizuka, T. Broad-leaf species composition in Cryptomeria japonica plantations with respect to distance from natural forest. For. Ecol. Manag. 2010, 259, 2133-2140. [CrossRef]

45. Hamao, S.; Miyashita, T.; Hagiwara, S.; Mori, Y. Seed dispersal by wintering birds in an urban space and relationship between gape width and fruit size. Jpn. J. Ornithol. 2010, 59, 139-147. [CrossRef]

46. Fukui, A.W. The role of the brown-eared bulbul Hypsypetes amaurotis as a seed dispersal agent. Res. Popul. Ecol. 1995, 37, 211-218. [CrossRef]

47. Noma, N.; Yumoto, T. Fruiting phenology of animal-dispersed plants in response to winter migration of frugivores in a warm temperate forest on Yakushima Island, Japan. Ecol. Res. 1997, 12, 119-129. [CrossRef]

48. Yoshikawa, T.; Isagi, Y. Dietary breadth of frugivorous birds in relation to their feeding strategies in the lowland forests of central Honshu, Japan. Oikos 2012, 121, 1041-1052. [CrossRef]

49. Kiyosu, Y. The Birds of Japan I; Kodansha: Tokyo, Japan, 1978. (In Japanese)

50. Lindenmayer, D.B.; Likens, G.E. Adaptive monitoring: A new paradigm for long-term research and monitoring. Trends Ecol. Evol. 2009, 24, 482-486. [CrossRef]

51. Karasti, H.; Baker, K.S. Digital data practices and the long term ecological research program growing global. Int. J. Digit. Curation 2008, 3. [CrossRef] 
52. Johnson, J.C.; Christian, R.R.; Brunt, J.W.; Hickman, C.R.; Waide, R.B. Evolution of Collaboration within the US Long Term Ecological Research Network. Bioscience 2010, 60, 931-940. [CrossRef]

53. Michener, W.K.; Porter, J.; Servilla, M.; Vanderbilt, K. Long term ecological research and information management. Ecol. Inform. 2011, 6, 13-24. [CrossRef]

54. Hobbie, J.E. Scientific accomplishments of the long term ecological research program: An introduction. Bioscience 2003, 53, 17-20. [CrossRef]

55. Alcantara, J.M.; Rey, P.J.; Valera, F.; Sanchez-Lafuente, A.M. Factors shaping the seedfall pattern of a bird-dispersed plant. Ecology 2000, 81, 1937-1950. [CrossRef]

56. Gonzales, R.S.; Ingle, N.R.; Lagunzad, D.A.; Nakashizuka, T. Seed Dispersal by Birds and Bats in Lowland Philippine Forest Successional Area. Biotropica 2009, 41, 452-458. [CrossRef]

57. McCay, T.S.; McCay, D.H.; Czajka, J.L. Deposition of exotic bird-dispersed seeds into three habitats of a fragmented landscape in the northeastern United States. Plant Ecol. 2009, 203, 59-67. [CrossRef]

(C) 2019 by the authors. Licensee MDPI, Basel, Switzerland. This article is an open access article distributed under the terms and conditions of the Creative Commons Attribution (CC BY) license (http://creativecommons.org/licenses/by/4.0/). 